\title{
Experiências brasileiras e o debate sobre comunicação e governança do risco em áreas contaminadas por chumbo
}

\author{
Brazilian cases and the debate about risk communication \\ and governance in areas contaminated by lead
}

Gabriela Marques Di Giulio ${ }^{1}$

Bernardino Ribeiro Figueiredo ${ }^{1}$

Lúcia da Costa Ferreira ${ }^{1}$

José Ângelo Sebastião Araújo Dos Anjos ${ }^{2}$

${ }^{1}$ Núcleo de Estudos e

Pesquisas Ambientais,

Universidade Estadual de

Campinas. Rua dos

Flamboyants 155, Cidade

Universitária Zeferino Vaz.

13083-867 Campinas SP.

gabrieladigiulio@yahoo.com.br

${ }^{2}$ Universidade de Salvador

\begin{abstract}
This investigation focused on lead contamination case studies in Brazil. The situations studied involve communities living in Santo Amaro da Purificação and Adrianópolis, in the northeast and south of Brazil, respectively. These communities have all had to live with environmental contamination and human exposure to lead as a consequence of industrial, mining and processing activities that were conducted by the same company for decades in a manner inconsistent with modern mining and industrial standards, with little control of environmental and human health impacts. The investigation sought to analyze the strategies of risk communication to local people, and to evaluate their engagement in risk management. The methodological approach included the analysis of newspaper articles, and interviews conducted with different stakeholders, such as residents, journalists, researchers and authorities. The results indicated the need to promote public involvement in the debate and in the decision-making process. The results also confirmed the hypothesis that associative models (represented by local neighborhood associations, for instance) are important for promoting and eliciting public participation in risk management.
\end{abstract}

Key words Risk communication, Risk governance, Lead contamination
Resumo No artigo são apresentados dois estudos de caso sobre contaminação por chumbo no Brasil. As situações estudadas referem-se a Santo Amaro da Purificação, nordeste, e Adrianópolis, sul, onde comunidades convivem com a contaminação ambiental e a exposição humana ao chumbo em decorrência das atividades industriais e de mineração desenvolvidas durantes décadas, por uma mesma empresa, de forma inconsistente com os padrões ambientais e de mineração, com pouco controle dos impactos ambientais e à saúde humana advindos. Os principais objetivos da investigação realizada foram analisar as estratégias de comunicação de risco adotadas junto às comunidades locais e avaliar o engajamento delas no processo de gerenciamento do risco. A metodologia aplicada incluiu análise de notícias jornalísticas e entrevistas realizadas com diferentes atores sociais, como moradores, jornalistas, pesquisadores e autoridades. Os resultados indicaram a necessidade de promover o envolvimento público no debate e no processo decisório. Os resultados validaram também a hipótese de que os modelos associativos (representados por associações de moradores, por exemplo) são importantes na promoção e no estímulo da participação pública no gerenciamento do risco.

Palavras-chave Comunicação de risco, Governança do risco, Contaminação por chumbo 


\section{Introdução}

Nos últimos anos, a comunicação de risco tem despertado o interesse de pesquisadores e de órgãos de governos, que reconhecem, frente à complexidade e às incertezas científicas, a necessidade de se estabelecer um diálogo entre aqueles que avaliam e gerenciam o risco e aquelas pessoas que de fato o vivenciam e de compreender que as controvérsias sociotécnicas, comuns em situações de risco, devem ser vistas como oportunidades para explorar alternativas possíveis e que o interesse coletivo é produto de negociações, conflitos sociais e alianças.

Dadas as características comuns acerca dos problemas relacionados ao risco e ao meio ambiente (fatos incertos, valores controvertidos, apostas elevadas e decisões urgentes), pesquisadores, governantes e representantes de órgãos governamentais têm reconhecido a necessidade de se colocar em prática uma nova estratégia de resolução, identificada como governança do risco ${ }^{1-5}$.

Nesta nova estratégia, o diálogo sobre a qualidade e a formulação de políticas para enfrentar problemas e riscos é considerado de fundamental importância e é estendido a todos os afetados pela questão. A abertura do diálogo e do processo decisório implica no reconhecimento de que a comunicação de risco não deve se limitar ao modelo do déficit de conhecimento, no qual os peritos comunicam os conhecimentos e suas "verdades científicas" para os leigos de modo a evitar que estes permaneçam na ignorância e na irracionalidade. Ao contrário, esse processo comunicativo deve envolver orientações e ferramentas estratégicas para que cientistas, governantes, técnicos e comunicadores saibam como construir uma atmosfera de confiança com todos os atores sociais envolvidos no gerenciamento de risco.

O interesse pela comunicação de risco é resultado do debate que tem ocorrido nas sociedades sobre abertura do processo decisório, justiça, confiança, participação pública e democracia; temas que têm tido papel central no desenvolvimento das agendas de pesquisa e política ${ }^{6}$. É resultado também da consciência de que é possível lidar de forma mais eficaz com as respostas públicas dadas aos riscos se, às pessoas afetadas pelas decisões sobre estes, é dada a oportunidade de participarem efetivamente do processo decisório, promovendo assim um processo analítico e deliberativo, no qual os efeitos da amplificação do risco são incluídos como um elemento importante nas decisões que são discutidas e tomadas $^{7}$. Entende-se por amplificação social do risco o "fenômeno pelo qual os processos de informação, as estruturas institucionais, o comportamento do grupo social e as respostas individuais dão forma à experiência social do risco, contribuindo para suas consequências"8.

Como observam os autores Funtowicz e Ravetz ${ }^{9}$, em situações de riscos, caracterizadas por incertezas científicas e pela própria complexidade envolvida no enfrentamento, "o conhecimento das condições locais ajuda a determinar quais dados são consistentes e relevantes, e também a definir os problemas que devem ser alvo das políticas".

Experiências de situações envolvendo riscos por exposição a substâncias perigosas ${ }^{10-12}$ evidenciam a necessidade de ir além do modelo de gerenciamento vigente e ainda bastante adotado, no qual a regulação dos riscos é baseada em avaliações técnicas e dados quantitativos, com pouca ou nenhuma atenção aos fatores sociais, culturais e econômicos envolvidos. É preciso abrir o processo decisório e criar novos espaços de negociação que desmonopolizem o conhecimento perito ${ }^{2}$ e envolvam de maneira construtiva, no debate e na pesquisa de soluções, todos os atores que direta ou indiretamente estejam ligados aos problemas identificados. Nesta prática, é reconhecido que, para os problemas complexos que se apresentam, existe mais de uma solução técnica e que a opção entre elas, longe de ser exclusivamente técnica, é também política, cultural e econômica ${ }^{13}$.

Evidencia-se, assim, a relevância da prática da governança do risco, termo que descreve um novo arranjo institucional no qual o processo decisório é coletivo, envolvendo atores governamentais e não governamentais. Nesta prática, o poder da sociedade é respeitado e a forma como as informações são coletadas, analisadas e comunicadas estão no centro da atenção ${ }^{1,3}$.

No conceito de governança do risco, está implícita a ideia de um processo decisório democrático e participativo relacionado ao gerenciamento do risco, entendendo participação como o compartilhamento do poder decisório do Estado em relação às questões relativas ao interesse público ${ }^{14}$ e como condição necessária para assegurar que as instituições governamentais atuem de forma responsável perante seus cidadãos, criando possibilidades para que indivíduos e grupos influenciem as decisões que os afetam (promovendo assim competência e capacidade para isso) e contribuindo para a estabilidade do sistema democrático ${ }^{15}$.

Na tentativa de contribuir para o debate teórico no qual se apóiam a comunicação e gover- 
nança do risco e analisar criticamente suas estratégias de comunicação e o envolvimento público na sua gestão, foram estudadas duas experiências brasileiras que envolviam contaminação ambiental e humana por chumbo. As experiências referem-se aos municípios de Adrianópolis, Vale do Ribeira - Sul e Santo Amaro da Purificação, Recôncavo Baiano - Nordeste (ver Figura 1). Nos dois casos, buscou-se analisar como as informações relacionadas ao risco da contaminação foram divulgadas para as comunidades afetadas; as relações estabelecidas entre os pesquisadores, as autoridades (locais, estaduais e federais) e os moradores e o engajamento das comunidades no processo de gerenciamento. Esta participação é analisada à luz da hipótese de que os modelos associativos, representados através de movimentos sociais e associações, podem contribuir ativamente para a produção de conhecimento e para as decisões que são tomadas, constituindo assim em atores fundamentais na governança do risco. A hipótese está relacionada com o que propõe Santos ${ }^{13}$ : para conseguir impor uma dinâmica permanente de democratização da ciência é importante que os grupos cujos interesses são afetados por qualquer atividade científica estejam bem representados nos processos de tomada de decisão em níveis local, nacional e global.

\section{Aspectos metodológicos}

A metodologia utilizada contemplou pesquisa empírica e análise de conteúdo de entrevistas com diferentes atores sociais (ver Quadros $1 \mathrm{e}$ 2). Para embasar a pesquisa empírica, recorreuse a uma pesquisa documental sobre notícias publicadas acerca de cada caso em diferentes momentos. As notícias permitiram, em um primeiro momento, identificar possíveis atores que poderiam ser entrevistados em cada caso. Posteriormente, esses nomes foram discutidos e definidos a partir da conversa com pesquisadores que realizaram estudos nos locais. Os nomes dos en-

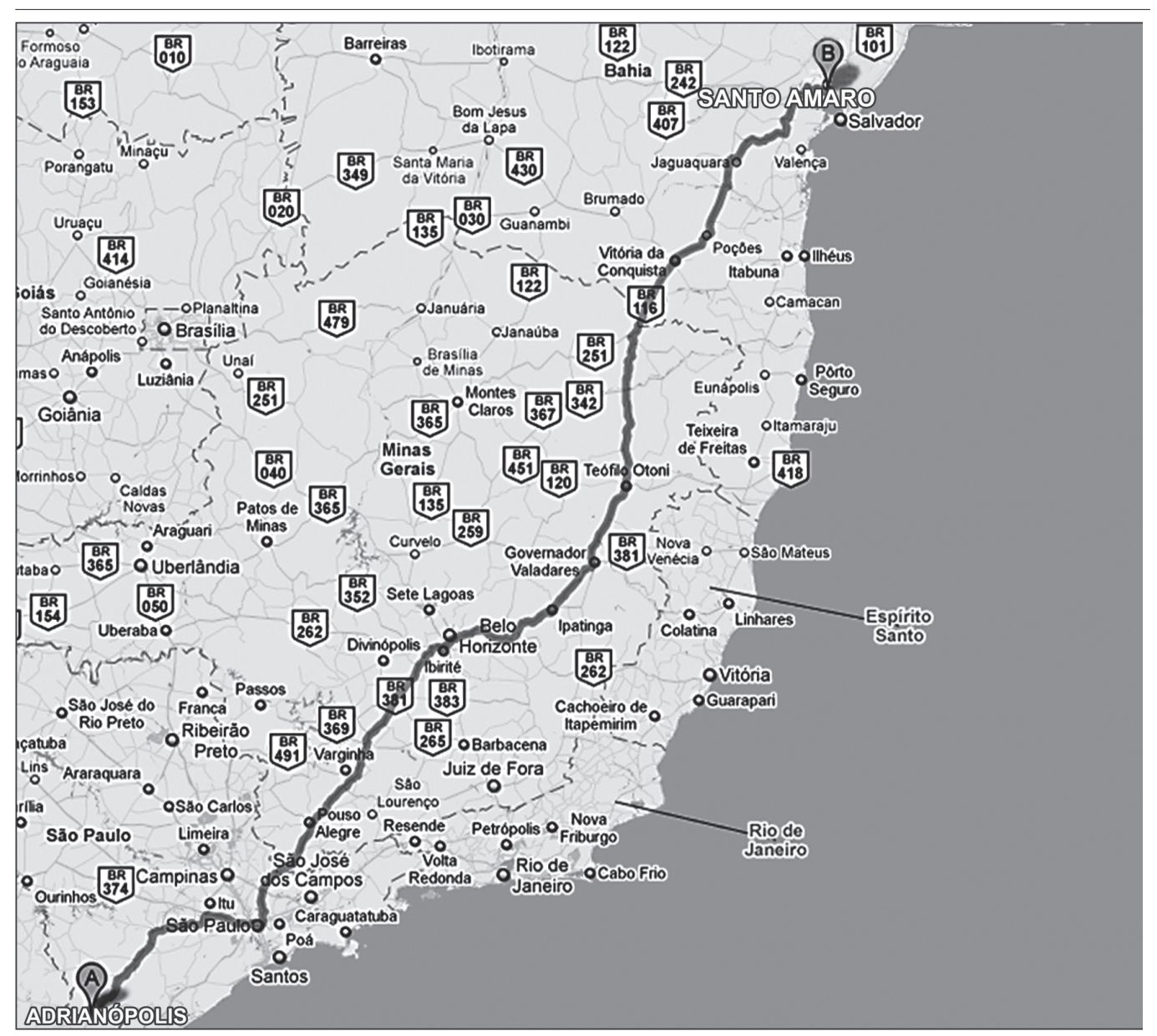

Figura 1. Localidades estudadas: Adrianópolis (PR) e Santo Amaro da Purificação (BA). Fonte: Google Maps 
trevistados também foram sugeridos e/ou confirmados durante as entrevistas realizadas, já que, ao término de cada entrevista, ao entrevistado era pedido indicação de pessoas com as quais poderíamos conversar sobre o assunto.

Ressalta-se que, para a realização da pesquisa empírica, utilizou-se uma adaptação da técnica conhecida como bola de neve (snowball), cujo objetivo fundamental é encontrar os sujeitos da pesquisa ${ }^{16}$. Esse método é usado, principalmente, em estudos que envolvem populações que não são facilmente acessadas, por diversos motivos (como problemas de saúde, questões sexuais, etc.) e, portanto, são estigmatizadas - entendendo-se estigma como a situação do indivíduo que está inabilitado para a aceitação social plena ${ }^{17,18}$.

Quadro 1. Entrevistados - Caso Adrianópolis (entrevistas realizadas em 2006)

\begin{tabular}{|c|c|}
\hline Grupos & Entrevistados \\
\hline Comunidade & $\begin{array}{l}\text { - Diretora de escola, acompanhou de perto as pesquisas realizadas na região } \\
\text { - Professor, também acompanhou de perto os estudos } \\
\text { - Morador e ex-funcionário da Plumbum A - VR ( que trabalhou como feitor na } \\
\text { Plumbum entre } 1951 \text { e } 1979 \text { e morador da Vila Mota há } 25 \text { anos) } \\
\text { - Morador e ex-funcionário da Plumbum B - VR (trabalhou na mina de } 1973 \text { a } 1981 \text { e } \\
\text { no forno de fundição de } 1985 \text { a } 1995\end{array}$ \\
\hline $\begin{array}{l}\text { Autoridades ou } \\
\text { funcionários } \\
\text { de órgãos } \\
\text { públicos } \\
\text { (municipais e } \\
\text { estaduais) }\end{array}$ & $\begin{array}{l}\text { - Vice-prefeito de Adrianópolis em 2006, prefeito eleito em } 2008 \\
\text { - Secretário local da saúde } \\
\text { - Vereador } \\
\text { - Secretário local de meio ambiente e agricultura } \\
\text { - Ex-vice-prefeito de Adrianópolis } \\
\text { Obs: Estas pessoas ocupavam os respectivos cargos em 2006, quando foram realizadas } \\
\text { as entrevistas. Com exceção do secretário de saúde, todos residiam há mais de duas } \\
\text { décadas no município e acompanharam o apogeu e o fechamento da Plumbum, bem } \\
\text { como a realização das pesquisas na região. Em uma nova visita a Adrianópolis, em } \\
\text { 2008, foi realizada uma reunião com o atual prefeito que, em 2006, ocupava o cargo } \\
\text { de vice, e seus assessores. } \\
\text { - Tecnólogo da Secretaria Estadual de Saúde } \\
\text { - Médica da Divisão de Zoonoses e Intoxicação da Secretaria Estadual de Saúde } \\
\text { - Bióloga, chefe da Divisão de Zoonoses e Intoxicação da Secretaria Estadual de Saúde } \\
\text { Obs: Os três profissionais acompanharam os estudos feitos na região e estiveram } \\
\text { envolvidos numa avaliação de risco realizada em Adrianópolis pela Secretaria Estadual } \\
\text { de Saúde. Uma nova reunião com esses profissionais foi realizada em } 2008 \text {. }\end{array}$ \\
\hline Jornalistas & $\begin{array}{l}\text { - Jornalista A - VR (trabalhava no jornal Gazeta do Povo em 2001, cobrindo as áreas } \\
\text { de saúde e geral. Reside atualmente nos Estados Unidos e já foi laureado com o } \\
\text { Prêmio Esso de Reportagem) } \\
\text { - Jornalista B - VR (trabalhava no jornal Folha de Londrina em 2001, cobrindo a área } \\
\text { de geral. É mestre em sociologia, doutor em ciências políticas e atualmente é professor } \\
\text { de uma universidade) } \\
\text { - Jornalista C (trabalhava no jornal Gazeta do Povo em 2001, produzindo matérias } \\
\text { sobre a área de saúde. Hoje é empresário na área de comunicação social - assessoria de } \\
\text { imprensa) }\end{array}$ \\
\hline $\begin{array}{l}\text { Pesquisadores } \\
\text { (meio } \\
\text { ambiente e } \\
\text { saúde) }\end{array}$ & $\begin{array}{l}\text { - Geólogo A (SGB/CPRM) } \\
\text { - Geólogo B (SGB/CPRM) } \\
\text { - Geóloga (SGB/CPRM) } \\
\text { Obs: Os três geólogos trabalham no Serviço Geológico do Brasil (SGB/CPRM) e } \\
\text { participaram dos estudos desenvolvidos pela Unicamp na região } \\
\text { - Toxicologista, da Universidade Estadual de Londrina (fez sua tese de doutorado sobre } \\
\text { avaliação e exposição humana ao chumbo no Vale do Ribeira) } \\
\text { - Química, do Instituto Adolfo Lutz (fez sua tese de doutorado também sobre } \\
\text { avaliação e exposição ao chumbo no Vale do Ribeira) } \\
\text { - Médico, professor da FCM-Unicamp }\end{array}$ \\
\hline
\end{tabular}


A partir das fontes identificadas, foi possível visualizar o estabelecimento de quatro categorias sociais ou grupos de entrevistados: jornalis- tas, pesquisadores, comunidade e autoridades (municipais, estaduais e federais). Esses grupos foram identificados a partir da ideia de agrupá-

Quadro 2. Entrevistados - Caso Santo Amaro da Purificação, BA (entrevistas realizadas em 2008)

\begin{tabular}{|c|c|}
\hline Grupos & Entrevistados \\
\hline Comunidade & $\begin{array}{l}\text { - Morador, ex-funcionário e presidente da Avicca (trabalhou como mecânico de } \\
\text { manutenção da empresa, entre maio de } 1993 \text { e dezembro de } 1993 \text {; morou durante } 18 \\
\text { anos há } 50 \text { metros da fábrica; é presidente da Avicca há cinco anos) } \\
\text { - Morador e ex-funcionário A - SA (aposentado, ocupa o cargo de coordenador } \\
\text { administrativo da Avicca e integra os conselhos do idoso, meio ambiente e defesa civil, } \\
\text { saúde e segurança da cidade; atuou na Cobrac de } 26 / 07 / 1960 \text { a 11/09/1965 e ocupou } \\
\text { os seguintes cargos: auxiliar de contabilidade, auxiliar de setor pessoal, auxiliar de } \\
\text { almoxarifado e controlador de custo) } \\
\text { - Morador e ex-funcionário B - SA (aposentado, trabalhou de } 1971 \text { a } 1990 \text { como } \\
\text { técnico em laboratório na Cobrac; fundou a Avicca mas atualmente não é membro da } \\
\text { associação; é uma das lideranças da cidade; disse fazer parte do "Senado", espécie de } \\
\text { grupo de aposentados da cidade que se reúnem na praça para conversar, entre outros } \\
\text { assuntos, sobre os problemas da cidade; quer formar um novo núcleo de assistências às } \\
\text { vítimas de Santo Amaro) } \\
\text { - Morador C (aposentado, nasceu em Santo Amaro, mora atualmente com a mãe, } \\
\text { personalidade importante da cidade e nacionalmente conhecida) } \\
\text { - Moradora e ex-vereadora D (é professora, dirige atualmente o Teatro de D. Canô, foi } \\
\text { vereadora da cidade entre } 1996 \text { e } 2000 \text { e foi presidente do movimento de luta pela } \\
\text { defesa do rio Subaé) }\end{array}$ \\
\hline $\begin{array}{l}\text { Autoridades } \\
\text { federais e } \\
\text { estaduais e } \\
\text { funcionários } \\
\text { de órgãos } \\
\text { públicos }\end{array}$ & $\begin{array}{l}\text { - Autoridade A (bióloga, coordenadora de meio ambiente, é funcionária da Secretaria de } \\
\text { Ciência e Tecnologia do governo estadual da Bahia; durante a pesquisa de campo era a } \\
\text { responsável pelo projeto para a descontaminação de Santo Amaro da Purificação) } \\
\text { - Autoridade B (é químico, coordenou o projeto de avaliação de risco em Santo Amaro } \\
\text { da Purificação, em 2001, após sua empresa ter vencido a concorrência para testar em } \\
\text { cinco áreas brasileiras a metodologia da ATSDR; sua empresa está no mercado desde } \\
1992 \text { e tem duas áreas de atuação: engenharia de tratamento de áreas subterrâneas e } \\
\text { estudos ambientais, incluindo estudos de avaliação de risco) }\end{array}$ \\
\hline Jornalistas & $\begin{array}{l}\text { - Jornalista A - SA (é jornalista e professor aposentado da UFBA; escreveu reportagem } \\
\text { sobre o caso em 1977; tem acompanhado o caso desde então e disponibiliza, na sua } \\
\text { homepage, diversas notícias sobre o caso. Atuou também como deputado estadual) } \\
\text { - Jornalista B - SA (atua na área há } 14 \text { anos, trabalha com meio ambiente } \\
\text { preferencialmente, mas também produz notícias sobre outros assuntos; produziu } \\
\text { notícias sobre o caso em 2005; uma de suas matérias sobre Santo Amaro foi } \\
\text { ganhadora de prêmio) }\end{array}$ \\
\hline $\begin{array}{l}\text { Pesquisadores } \\
\text { (meio } \\
\text { ambiente e } \\
\text { saúde) }\end{array}$ & $\begin{array}{l}\text { - Pesquisador A (é médico, pesquisador e professor da UFBA e desenvolve pesquisas } \\
\text { em Santo Amaro da Purificação desde a década de 1970) } \\
\text { - Pesquisadora B (é química e professora do CEFET de Santo Amaro da Purificação, } \\
\text { desenvolve pesquisa sobre a contaminação e reside atualmente na cidade) } \\
\text { - Pesquisadora C (é nutricionista e professora da UFBA, fez pesquisa sobre a } \\
\text { contaminação em Santo Amaro da Purificação avaliando risco à saúde humana através } \\
\text { da ingestão de alimentos) } \\
\text { - Pesquisador D (é engenheiro civil e professor da UFBA, trabalhou no projeto Purifica } \\
\text { e atualmente faz parte da comissão científica do projeto de descontaminação da } \\
\text { Secretaria de Ciência e Tecnologia da Bahia) } \\
\text { - Pesquisador E (é pesquisador e coordenador de curso de engenharia e tecnologia da } \\
\text { Unifacs, desenvolveu dissertação e tese de doutorado sobre o problema da } \\
\text { contaminação por chumbo; ajudou no delineamento desta pesquisa) }\end{array}$ \\
\hline
\end{tabular}


los de acordo com as suas ocupações, responsabilidades e formas de atuação no caso.

As entrevistas foram realizadas com o objetivo de identificar as percepções e as atitudes dos moradores expostos à contaminação por chumbo, compreender como as informações relacionadas a esse risco foram divulgadas para as comunidades afetadas e verificar as relações estabelecidas entre pesquisadores, autoridades (locais, estaduais e federais) e moradores e o engajamento das comunidades no processo de gerenciamento de risco.

\section{Descrição dos casos}

Com uma população estimada em 6,7 mil habitantes pelo IBGE, a cidade de Adrianópolis está localizada no Vale do Ribeira, a cerca de 130 quilômetros de Curitiba (PR). No município funcionou entre 1945 e 1995 a usina Plumbum Mineração e Metalurgia Ltda, pertencente ao grupo Trevo, que operava o beneficiamento e o refino de minérios de chumbo produzidos nas minas da região ou importados de outros países. Estimase que durante os 50 anos de funcionamento da Plumbum foi lançada na atmosfera grande quantidade de material particulado rico em chumbo, que se depositou nos solos de áreas adjacentes.

Diversos estudos foram feitos na localidade para verificar os efeitos da exposição ao chumbo no ambiente e na população residente no município, especialmente nas comunidades residentes próximo à usina. Um desses estudos, realizado por um grupo de pesquisadores da Unicamp, apontou que parte da população de duas comunidades localizadas na zona rural de Adrianópolis - Vila Mota e Capelinha (próximas à usina) apresentava níveis médios elevados de chumbo em sangue. Os resultados não configuravam a existência de uma situação alarmante, porém $60 \%$ das amostras coletadas nestas comunidades apresentaram concentrações de chumbo superiores a 10 microgramas por decilitro $(\mu \mathrm{g} / \mathrm{dL}) \mathrm{de}$ sangue, aceito internacionalmente como limite máximo de normalidade, segundo o Center for Disease Control and Prevention (CDC). Aproximadamente $13 \%$ das amostras apresentaram concentrações superiores a 20 microgramas por decilitro, o que já impunha a adoção de medidas de intervenção ambiental na área e de acompanhamento médico ${ }^{19-21}$.

Esse estudo apontou que a fonte primária de contaminação do solo e da poeira, nas áreas peridomiciliares e intradomiciliares, foi a Plumbum com o lançamento direto do material particula- do na atmosfera. Hoje, além dos solos contaminados, o estudo revelou que vários alimentos plantados em cultivares de hortas, nos quintais das casas próximas à Plumbum, excedem os limites de concentração de chumbo estabelecidos pela legislação brasileira e, por isso, contribuem para a contaminação desses moradores ${ }^{22}$.

Em 2008, a Secretaria de Saúde do Paraná divulgou o relatório de avaliação de risco de Adrianópolis, feito a pedido do Ministério da Saúde. O relatório seguiu a metodologia da ATSDR (Agency for Toxic Substances and Disease Registry) e incluiu avaliação da informação do local, respostas às preocupações da comunidade, seleção dos contaminantes de interesse, identificação e avaliação das rotas de exposição, caracterização das implicações para a saúde e conclusões e recomendações.

O relatório tece diversas recomendações e ações para as áreas de saúde e meio ambiente, sugerindo inclusive que uma das medidas poderia ser a remoção dos moradores que residem próximo à área da Plumbum.

O município de Santo Amaro da Purificação, localizado no Recôncavo Baiano a cerca de 70 quilômetros de Salvador, tem uma população estimada em cerca de 60 mil habitantes e sua história recente está associada à exposição ambiental e humana ao chumbo também como consequência das atividades exercidas entre 1960 e 1993 por uma usina de produção de lingotes, pertencente ao mesmo grupo de empresa que poluiu Adrianópolis.

Diversos estudos foram feitos na localidade para avaliar a exposição ambiental e humana ao chumbo e a outros metais. Já na década de 1970 um relatório técnico apontou a empresa como responsável pela contaminação dos compartimentos ambientais da área e morte de animais que pastavam próximo a área da usina, e outro estudo apresentou evidências de contaminação do rio Subaé (que corta a cidade) por chumbo e cádmio, provenientes da indústria ${ }^{23}$.

Pesquisas realizadas na década de 1980 apontaram que a fundição primária de chumbo poluiu intensamente a cidade e que seus trabalhadores e os moradores de regiões próximas à usina tinham sido particularmente afetados. Em 1995, dois anos após o fechamento da empresa, outro estudo evidenciou elevadas concentrações de chumbo e cádmio em sedimentos e moluscos de todo o ecossistema ao norte da Baía de Todos os Santos, onde deságua o rio Subaé, após receber a carga poluidora da fundiçãa ${ }^{23}$. Outros dois estudos conduzidos por Dos Anjos ${ }^{24}$ confirma- 
ram a gravidade da situação, estimando em cerca de 490 mil toneladas de escórias deixadas pela empresa.

Parte desta escória, segundo relatos de Carvalho et al. ${ }^{23}$, foi doada aos moradores do município, que frequentemente a usavam para pavimentar as vias de acesso e os quintais de sua casa. A prefeitura local usou grandes quantidades dessa escória para pavimentar muitas ruas e lugares públicos da cidade. Em 1998, durante as obras de saneamento básico do programa Bahia Azul, do governo baiano, foram escavadas diversas ruas próximas à fundição, expondo a camada de escória. A escória revolvida foi deixada nas portas das residências, o que aumentou ainda mais o risco de contaminação da população.

Estudos conduzidos no final da década de 1990, envolvendo 44 crianças de 1 a 4 anos de idade (de 131 famílias), residentes a uma distância de até mil metros ao redor da fundição de chumbo, apontaram que $88 \%$ delas tinham níveis de chumbo no sangue superiores a $10 \mathrm{mi}-$ crogramas por decilitro de sangue. Os resultados mostraram que $32 \%$ excediam $20 \mu \mathrm{g} / \mathrm{dL}^{23}$.

No município também foi realizada uma avaliação de risco, em 2002, a pedido do Ministério da Saúde e conduzida pela empresa Ambios Engenharia e Processos Ltda. A avaliação seguiu o modelo da ATSDR e propôs diversas recomendações nas áreas ambiental e de saúde, inclusive a remoção dos moradores que residem em habitações até 500 metros da usina ${ }^{25}$.

\section{Resultados}

\section{Adrianópolis - Vale do Ribeira}

Apesar de diversos estudos terem sido conduzidos em Adrianópolis por diferentes grupos de pesquisa, este artigo abordou as experiências do estudo feito pela Unicamp e é dentro desta perspectiva que as relações entre pesquisadores, autoridades e moradores, bem como as estratégias de comunicação de risco são analisadas.

Os depoimentos dos pesquisadores evidenciaram que houve uma preocupação em como abordar a comunidade a ser estudada e, posteriormente, transmitir os resultados obtidos.

"Em todos os municípios pesquisados, a primeira abordagem foi sempre com o prefeito e/ ou secretário de saúde do município. ... Explicávamos os objetivos da pesquisa, comentávamos sobre o retorno dos dados ao município. ...Também explicávamos os objetivos da pesquisa e a necessidade de uma reunião com os pais ou parentes próximos" (toxicologista)

Os depoimentos, todavia, evidenciaram que não houve um plano previamente estabelecido de comunicação de risco, entendendo esse processo comunicativo como a promoção constante de um diálogo com a comunidade, autoridades (nos diversos âmbitos) e demais atores sociais interessados, como a própria mídia.

"Esse tipo de informação tem de ser dado sempre com um certo cuidado, mesmo para os técnicos das instituições locais porque também a interpretação desses dados não é muito simples. ... As expressões relacionadas à toxicologia são sempre alarmantes, têm conotação, às vezes, até pejorativa, estigmatizante. ... Basicamente foram feitas duas formas de comunicação. Uma mais coletiva, quando obtivemos os resultados do ponto de vista coletivo. ... Depois, teve uma fase de apresentação, vamos dizer, mais individual dos resultados. ...De qualquer modo houve um certo desrespeito por parte da imprensa em geral com o que estava acontecendo e isso causou problema. Acho que isso serve para aprendermos a ter uma certa cadência diferente em relação ao contato com a imprensa. ... Talvez juntamente com a apresentação da pesquisa para as instituições e população locais ter a imprensa já avisada e esclarecida" (médico)

Os problemas advindos com a divulgação "apressada" do problema da contaminação em Adrianópolis pela mídia estremeceram a relação entre pesquisadores e comunidade e trouxeram prejuízos à relação de confiança que deve ser estabelecida entre estes atores para a condução dos estudos. A cidade passou a ser conhecida como "cidade do chumbo" e seus moradores enfrentaram diversos problemas de estigma (preconceito, prejuízos econômicos e desvalorização de suas terras). Os depoimentos comprovaram esses efeitos da amplificação social do risco.

"Adrianópolis ficou conhecida como a cidade do chumbo. Todos pensavam que aqui só tinha contaminação, que todos estavam contaminados. ... O povo daqui não consegue mais emprego, em lugar nenhum. ... Outro dia, meus colegas de Curitiba disseram: 'Fica mais longe de nós porque não queremos ser contaminados também'. Isso dá vergonha na gente" (vereador)

A repercussão negativa, no entanto, também trouxe um aspecto positivo: os pesquisadores começaram a se preocupar mais com a comunicação de risco, como mostraram os depoimentos:

"Essa pesquisa mostrou que precisamos incluir numa pesquisa pessoas treinadas para isso, 
que saibam como comunicar riscos, soluções técnicas numa linguagem mais acessível para que as pessoas compreendam e saibam o que fazer com a informação" (médico)

Com relação ao envolvimento da comunidade no processo de avaliação e gerenciamento de risco, esta ficou limitada à participação dos moradores no estudo (permitindo a coleta de amostras de sangue, poeira das casas, solos e alimentos cultivados).

"A relação com os moradores foi boa. Eles aderiram bem ao projeto sem nenhum questionamento. ... Havia uma falta de conhecimento por parte deles sobre a questão da exposição humana ao chumbo" (química)

A ausência de um movimento associativo que tivesse forte atuação (como associações de bairro, de ex-trabalhadores ou ainda de possíveis vítimas da contaminação) pode ter sido um fator que colaborou para que a comunidade não tivesse voz ativa e não participasse do processo de gerenciamento de risco. Há também outros fatores relevantes que pesaram para que a participação pública na gestão do risco não ocorresse: as diferentes percepções do risco por parte da comunidade (associadas muitas vezes à negação do perigo e/ou à necessidade de esquecê-lo, para retomar a vida cotidiana sem ter de enfrentar mais problemas como aceitação social ou de ordem econômica); a ideia de que o problema da contaminação é usado com motivações políticas; a crença de que a solução do problema cabe apenas aos governantes e aos técnicos, que têm os conhecimentos e recursos necessários para isso; a falta de informação; a premissa embutida na concepção de gestão de risco que não leva em conta o conhecimento que aquelas pessoas expostas têm sobre os problemas que enfrentam. Isso é evidenciado nos seguintes depoimentos:

"Lamento que as pessoas de lá não tenham vontade de mudar de vida. Acho que em Adrianópolis falta as pessoas acreditarem nelas mesmas, saberem que tudo que pode acontecer depende delas" (ex-vice prefeito)

"Tudo começa pela educação. Mas, não tem ninguém fazendo esse trabalho de conscientizar as pessoas a fazerem isso ou aquilo para não continuar a conviver com a contaminação do chumbo. ... A população já está cansada. Eles dizem que as pessoas vêm aqui, tiram o sangue deles, mas não resolvem nada" (vice-prefeito, prefeito eleito em 2008)

\section{Santo Amaro da Purificação}

As preocupações e estratégias sobre como abordar a comunidade e comunicar os resultados das pesquisas variaram em função dos diferentes grupos de pesquisadores que realizaram estudos no município baiano.

"Quando comecei minhas pesquisas em Santo Amaro ainda não existia um Comitê de Ética e Pesquisa, que é importante principalmente sobre como coletar as amostras e sobre como devolver os resultados dos estudos para a população estudada. Mas sempre primamos por devolver os resultados a cada interessado. Nossa abordagem envolvia reuniões antes, durante e depois com a comunidade" (pesquisador A)

"Durante nosso projeto, a nossa abordagem era de bater na porta das casas dos moradores, explicar e pedir para entrar. Sentimos desconfiança" (pesquisador D)

Somente um entrevistado informou que, durante a avaliação de risco que coordenava, havia estratégias de comunicação, seguindo uma metodologia, para abordar a comunidade.

"Em relação ao contato com a população, a receptividade foi muito boa. ... Nossa abordagem envolvia técnicas, estratégias de comunicação, seguindo as normas da ATSDR. ... A questão básica era a transparência, a discussão da nossa visão com a população, as técnicas de aproximação, de contato sempre inseridas num contexto moral-ético. ... A aproximação acadêmica é problemática, a população se vê como substrato de análise e não como beneficiada, com a possibilidade de ser indenizada" (autoridade B)

O problema da contaminação por chumbo também ganhou repercussão na mídia, o que contribuiu para o processo de amplificação social do risco. Os depoimentos mostraram também que, apesar da divulgação midiática e da preocupação que alguns pesquisadores tiveram em informar a comunidade sobre o problema ao qual estava exposta, há falta de informação entre os moradores e, como consequência, há percepções bastante distintas do risco.

"Acho que os moradores conhecem o problema de diferentes formas, o grau de interação varia. Há os céticos e há pessoas aterrorizadas com o problema. ... É preciso ter acesso à informação" (pesquisador D)

"As pessoas preferem negar o problema. Tudo é passado de maneira pejorativa. Conheço 
pessoas que rasgaram suas carteiras de trabalho e tiraram novas, para não constar o trabalho na Cobrac. Toda a cidade sofre com a contaminação e com o preconceito" (morador e ex-funcionário $\mathrm{B}$ )

Essas observações sobre as percepções de risco, a informação e a amplificação social do risco repercutiram, por parte dos pesquisadores entrevistados, em uma maior preocupação com as estratégias de comunicação de risco em estudos e ações futuras.

"Espero que seja feito em Santo Amaro o que deveria ter sido feito lá há muito tempo. O que é de direito. Informação e conhecimento para as pessoas, para que elas conheçam a dimensão real do problema" (pesquisadora $\mathrm{C}$ )

Com relação ao envolvimento da comunidade no processo de avaliação e gerenciamento de risco, observou-se que ele foi motivado, principalmente, pelos problemas de saúde que parte da comunidade enfrenta e associa à contaminação por chumbo. Neste sentido, uma associação foi criada com o objetivo de mobilizar as pessoas em torno de um projeto político comum: o direito ao reconhecimento das vítimas por contaminação por chumbo, à reparação financeira e previdenciária, ao atendimento médico especializado e à reparação ambiental do município, o que inclui ações de descontaminação e intervenção.

"Em 2000, conheci dois deputados que faziam parte da comissão de meio ambiente e tinham os trabalhos dos pesquisadores. Fizemos audiência pública... e achamos que tínhamos que montar uma associação" (morador e ex-funcionário $\mathrm{B}$ )

"Hoje a Avicca conta com 1,2 mil associados, mas queremos chegar a cinco mil pessoas, queremos cadastrar todas as vítimas. ... Estamos estudando uma ação contra o governo. ... Nossa luta é que a contaminação por chumbo não é reconhecida como doença ocupacional" (morador e presidente da Avicca)

A associação das vítimas tem atuado no sentido de cobrar e exercer pressão política para que algo seja feito, inclusive no nível federal, já que seu presidente esteve reunido com o Presidente da República, em agosto de 2005, para entregar um relatório e exigir maior atenção ao município. A atuação da associação, porém, é limitada ao acesso a informações e à consulta (também limitada, já que as autoridades definem, previamente, os assuntos nos quais as opiniões dos cidadãos seriam solicitadas). Nos depoimentos colhidos, observa-se que a associação das vítimas busca um espaço maior e se reconhece como um ator importante no processo de remediação do problema.

"Tudo que for fazer sou a favor, ajudaria, mas não quero que descartem a saúde. Os órgãos tentaram impor o que querem, não querem ouvir o que queremos. Não queremos que cheguem aqui e coloquem a tinta que querem. Não vamos mais aceitar de cabeça baixa. Temos que estudar, ter parâmetros, conhecer leis para contestar. O papel da Avicca é fundamental" (morador e presidente da Avicca)

A falta de conscientização do problema e a própria questão cultural, que estaria associada a uma falta de vontade da comunidade em lutar, foram apontadas por uma entrevistada como pontos relevantes no pouco engajamento dos moradores no processo de gerenciamento do risco.

"O problema de Santo Amaro é a letargia social, a falta de ação social (...) Falta conscientização do problema. Isso é uma herança trágica do sentimento de servilismo. ..." (moradora e exvereadora D)

\section{Discussão}

Os dois casos estudados mostram que a prática da comunicação é condição necessária para informar e integrar o público no processo de solução das situações de riscos e para construir uma atmosfera de confiança entre os atores sociais envolvidos no enfrentamento. Apesar disso, esse processo comunicativo ainda ocorre pouco e com dificuldades, prejudicando o diálogo e a parceria entre quem avalia os riscos e aqueles que os vivenciam.

No caso de Adrianópolis, houve uma preocupação em como abordar a comunidade, informá-la sobre a realização dos estudos, obter o consentimento para a coleta de amostras e retornar os resultados obtidos. Entretanto, não houve um plano pré-estabelecido que conjugasse todos essas necessidades e que ainda envolvesse a divulgação dos dados para a mídia e para outros órgãos governamentais, no caso a Secretaria de Saúde do Estado do Paraná.

Os pesquisadores, segundo os relatos, foram surpreendidos pela divulgação midiática sobre o problema da contaminação por chumbo em Adrianópolis (a divulgação, naquele momento, foi motivada por uma denúncia de um político local e embasada em dados parciais divulgados por outro grupo de pesquisa) e pelos efeitos adversos resultantes da exposição dessas informações na mídia local, regional e nacional. 
O que aconteceu posteriormente, como a estigmatização do local e das pessoas e a quebra de confiança na relação entre pesquisadores e comunidade, pesou fortemente para que esses pesquisadores admitissem a necessidade de um plano de comunicação de risco, antes mesmo de dar início aos estudos, e de contar com um profissional especializado no assunto dentro da equipe em pesquisas futuras.

Em Santo Amaro da Purificação, a situação não foi muito distinta, como relatam alguns entrevistados. As estratégias de comunicação de risco - limitadas à abordagem da comunidade, obtenção de consentimento e retorno dos resultados - variaram em função dos estudos realizados e dos grupos de pesquisas envolvidos (alguns grupos se sensibilizaram para esta questão, outros não).

Entretanto, os depoimentos dos moradores evidenciam que há necessidade de mais divulgação e debate sobre o problema, mostrando que a comunicação de risco, entendida como um diálogo de mão dupla no qual peritos e público discutem o problema em pé de igualdade, colocando abertamente suas preocupações e anseios, ainda não é uma prática corrente.

Ao atentar para a questão da comunicação de risco é importante fazer uma ressalva: esse processo comunicativo está diretamente relacionado aos diversos fatores psicológicos, econômicos, culturais, sociais e políticos que estão envolvidos nas percepções e atitudes das pessoas frente aos perigos e problemas que enfrentam ${ }^{26}$. As estratégias de abertura de diálogo e os seus desdobramentos são afetados diretamente por esses fatores. Neste sentido, é preciso pensar nas diferenças das duas comunidades envolvidas nestas situações de risco.

Adrianópolis é um município pequeno, com menos de sete mil habitantes, encravado no Vale do Ribeira e que teve uma importância econômica no século passado devido às atividades de mineração. Santo Amaro da Purificação tem cerca de 60 mil habitantes e uma importância histórica e cultural destacada no cenário baiano. Já no passado sua vocação agrícola, com destaque para o cultivo da cana-de-açúcar, colocava o município em posição de destaque no Recôncavo Baiano.

Como noticiou o jornal paranaense Gazeta do Povo, em 10/01/2005, numa comparação entre essas duas localidades, a cidade paranaense "sofre no ostracismo as sequelas deixadas pela mesma mineradora. Talvez porque Adrianópolis não tenha um filho ilustre para cantar as dores de seus conterrâneos", numa referência à com- posição de Caetano Veloso sobre as dores de quem foi contaminado pelo chumbo em sua cidade natal.

A comparação do jornalista mostra que, de fato, nestas situações de risco os fatores econômicos, culturais, políticos e sociais vigentes em cada comunidade têm forte peso e podem contribuir para atrair ou não a atenção pública e a política para o problema e para a maior vulnerabilidade de uns do que de outros.

No processo de engajamento das comunidades, cujos interesses estão diretamente relacionados às decisões que serão tomadas no gerenciamento do risco, pesam também os efeitos (sociais, econômicos e, sobretudo, na qualidade de vida) que esses indivíduos têm sentido devido à exposição ambiental e humana ao chumbo. Nos dois municípios, os efeitos econômicos são fortes. Já os efeitos na saúde foram e continuam sendo mais sentidos na população de Santo Amaro da Purificação, devido à maior gravidade e extensão da exposição.

A maioria dos esforços relacionados à prática da comunicação de risco, colocados em prática pelos grupos de pesquisadores em cada localidade, foi válida, mas não obteve o sucesso esperado, no sentido de envolver orientações e ferramentas estratégicas para que cientistas, governantes, técnicos e comunicadores soubessem como construir uma atmosfera de confiança com todos os atores sociais envolvidos no gerenciamento de risco. Isso porque tais esforços falharam em considerar também que os indivíduos, mesmo quando vivem em áreas consideradas de risco, têm forte apego ao local onde moram e que o ambiente onde estas pessoas nasceram e cresceram é de fundamental importância para a construção e a continuidade de suas identidades ${ }^{27}$.

Há também outro fator relevante no processo de comunicação de risco que, consciente ou inconscientemente, é pouco considerado pelos peritos e pesquisadores: a necessidade de reconhecer que aquelas pessoas que vivenciam de fato o risco também possuem seu próprio conhecimento sobre os problemas que as atingem e que, portanto, o diálogo com elas tem de ser permeado pela premissa de que o conhecimento leigo não é irracional e que julgamentos de valor estão presentes em todas as fases do processo de gestão de riscos, dividindo também os peritos ${ }^{2}$.

Se isso não é reconhecido, a participação pública no gerenciamento do risco é afetada, prejudicando que o processo decisório seja coletivo e que o poder da sociedade seja respeitado. A própria separação entre o conhecimento tido como 
técnico ou especializado do chamado conhecimento leigo tende a legitimar a autonomia dos cientistas e dos especialistas na tomada de decisões sobre assuntos considerados "de especialidade", ao mesmo tempo que remete o cidadão para um espaço de silêncio, atribuindo-lhe o estatuto de mero observador e consumidor da ciência ${ }^{13}$.

Esse pensamento está longe do que propõe a prática da governança do risco, que considera que o processo decisório deve ser coletivo, respeitando-se o poder da sociedade.

Nos dois casos estudados, ao analisar a questão da governança do risco, nota-se a validade da hipótese de que os modelos associativos, representados através de movimentos sociais e associações, podem contribuir ativamente para a produção de conhecimento e para as decisões que são tomadas e que constituem, portanto, atores fundamentais neste novo arranjo institucional.

No caso de Adrianópolis, não havia nenhuma associação reconhecida que tenha sido citada pelos entrevistados e que atuasse de forma organizada, motivada por um projeto político comum. A ausência de um movimento associativo pode ter sido um fator que colaborou para que a comunidade não tivesse voz ativa e não participasse do processo de gerenciamento de risco.

No caso de Santo Amaro da Purificação, a atuação da Avicca, especialmente, tem exercido pressão política e tem tido importância para que as discussões sobre o gerenciamento do risco não fiquem apenas nas mãos dos técnicos e dos governantes. Todavia, é necessário reconhecer que a atuação desse modelo associativo ainda é pequena e que este representa os interesses de um grupo limitado (ex-trabalhadores e aqueles que se consideram vítimas da contaminação). A atuação da Avicca está limitada a uma participação institucional, já que a associação é convidada oficialmente a participar das reuniões realizadas pelo governo baiano, como representante da sociedade civil, e, pelo menos teoricamente, tem seus desejos ouvidos e respeitados. O envolvimento da associação estaria limitado, assim, ao acesso à informação e à consulta pública; mas ainda estaria longe da participação pública, que envolve decisões que são tomadas conjuntamente entre tomadores de decisão e comunidade e onde o diálogo e a negociação entre os atores sociais servem também para transformar as opiniões de representantes do público e dos órgãos oficiais ${ }^{28}$.

\section{Considerações finais}

A análise dos dois casos brasileiros evidencia que a abertura do diálogo e do processo decisório, nestas situações de risco por contaminação, caminha a passos curtos, apesar da evidente necessidade de se reconhecer que, dadas as características comuns quanto aos problemas relacionados ao risco e ao meio ambiente, é preciso colocar em prática uma nova estratégia de resolução de tais problemas, que considere o envolvimento do público leigo no diálogo, sua influência na pauta dos temas a debater e seu poder nas decisões a serem tomadas.

As limitações da ciência, as influências subjetivas no processo de avaliação de risco, as controvérsias existentes sobre as ações de manejo (geralmente mascaradas e pouco difundidas) e a importância de se estabelecer uma relação de confiança entre os atores envolvidos no enfrentamento do risco apontam para a importância de envolver as comunidades, cujos interesses são direta e indiretamente afetados pelas decisões na estruturação e na elaboração das ações quanto ao gerenciamento do risco.

Para que isso ocorra, como mostraram os dois casos, é preciso abrir o diálogo e o processo decisório e, portanto, colocar em prática uma comunicação de risco que de fato considere os elementos sociais, culturais e econômicos envolvidos, parta do pressuposto de que aquelas pessoas afetadas pelas decisões devem estar envolvidas no processo de sugestões e escolhas de alternativas e instaure uma estratégia aberta e coletiva de produção de conhecimento.

A análise dos resultados também valida a hipótese de que os modelos associativos (formados por integrantes da sociedade civil) cumprem papel relevante na promoção efetiva da participação pública no gerenciamento do risco e, portanto, são atores sociais importantes na governança do risco.

Ao comparar os dois casos estudados, é possível verificar que há diferenças quanto ao envolvimento e participação daqueles indivíduos cujos interesses são afetados diretamente pelas decisões que são tomadas com relação ao manejo do risco. O envolvimento da comunidade de Santo Amaro da Purificação é maior e a população começa a ser ouvida, mesmo que de forma limitada, no processo de discussão e de escolha de ações, resultado também da mobilização e da atuação de modelos associativos como a Avicca. 


\section{Colaboradores}

GM Di Giulio é responsável pela condução teórica e metodológica da pesquisa e trabalhou na elaboração e na redação final do texto; BR Figueiredo e LC Ferreira trabalharam na orientação e discussão teórica e metodológica da pesquisa, bem como na elaboração e redação final do texto; JASA dos Anjos trabalhou na orientação e acompanhamento dos trabalhos de campo e na revisão crítica do texto.

\section{Agradecimentos}

Os autores agradecem o apoio financeiro da Fundação de Amparo à Pesquisa do Estado de São Paulo (FAPESP), da Coordenação de Aperfeiçoamento de Pessoal de Nível Superior (CAPES) e do Conselho Nacional de Desenvolvimento Científico e Tecnológico (CNPq).

\section{Referências}

1. Alcântara CH. Usos y abusos del concepto de gobernabilidad, 1998. International Social Science Journal, no 155. Unesco. [acessado 2008 jul 9]. Disponível em: http://www.diba.es/fl/fitxers/pf-050.pdf

2. Guivant JS. A governança dos riscos e os desafios para a redefinição da arena pública do Brasil. In: Ciência, Tecnologia + Sociedade - Novos Modelos de Governança. Brasília, 06 a 11 de dezembro de 2004. [Documento da Internet] [acessado 2008 out 1]. Disponível em: http://www.iris.ufsc.br/pdf/ A\%20governa\%5B1\%5D...pdf

3. Jasanoff S, Martello ML, organizadores. Earthly Politics: local and global in Environmental Governance. Massachusetts; MIT Press; 2004.

4. Gaudin JP. A governança moderna, ontem e hoje: alguns esclarecimentos a partir das políticas públicas francesas. In: Curso de Gestão Urbana das Cidades. 14 a 26 de maio de 2001. Belo Horizonte/MG: EG/FJP, WBI, LILP, ESAF, IPEA. [Documento da Internet] [acessado 2008 out 1]. Disponível em: http://www.eg.fjp.mg.gov.br/gestaourbana/arquivos/ abertura/ab1.htm

5. Renn O. Risk governance: coping with uncertainty in a complex world. London: Earthscan; 2008.

6. Horlick-Jones T, Sime J, Pidgeon N. The social dynamics of environmental risk perception: implications for risk communication and practice. In: Pidgeon N, Kasperson RE, Slovic P. The Social Amplification of Risk. Cambridge: Cambridge University Press; 2003. p. 262-285.

7. Renn O. Social amplification of risk in participation: two case studies. In: Pidgeon N, Kasperson RE, Slovic P. The Social Amplification of Risk. Cambridge: Cambridge University Press; 2003. p. 374-401.

8. Kasperson RE, Ren O, Slovic P, Brown HS, Emel J, Goble R, Kasperson JX, Ratick S. The social amplification of risk: a conceptual framework. In: Kasperson JX, Kasperson RE. The social contours of risk: publics, risk communication and the social amplification of risk. London: Earthscan; 2005. p.99-114.

9. Funtowicz S, Ravetz J. Ciência pós-normal e comunidades ampliadas de pares face aos desafios ambientais. Hist Cienc Saude-Manguinhos 1997; 4(2):219-230.

10. Di Giulio GM. Divulgação científica e comunicação de risco: um olhar sobre Adrianópolis, Vale do Ribeira [dissertação]. Campinas (SP): Instituto de Geociências, Unicamp; 2006. 
11. Di Giulio GM, Pereira NM, Figueiredo BR. Lead contamination, the media and risk communication: a case study from the Ribeira Valley, Brazil. In: Liverman DGE, Pereira C, Marker B, organizadores. Communicating Environmental Geoscience. London: Geological Society Special Publications; 2008. v. 305, p. 63-74.

12. Di Giulio GM, Pereira NM, Figueiredo BR. O papel da mídia na construção social do risco: o caso Adrianópolis, no Vale do Ribeira. História, Ciências, Saúde - Manguinhos 2008; 15(2):293-311.

13. Santos BS, organizador. Semear outras soluções - os caminhos da biodiversidade e dos conhecimentos rivais. Rio de Janeiro; Civilização Brasileira: 2005.

14. Dagnino E, Olvera AJ, Panfichi A. organizadores. Para uma outra leitura da disputa pela construção democrática na América Latina. In: Dagnino E, Olvera AJ, Panfichi A, organizadores. A Disputa pela Construção Democrática na América Latina. São Paulo: Paz e Terra; 2005. p. 13-91.

15. Ashford NA, Rest KM. Public participation in contaminated communities. Center for Technology, Policy and Industrial Development. Cambridge: Massachusetts Institute of Technology; 1999. [Documento da Internet] [acessado 2008 ago 6]. Disponível em: http://web.mit.edu/ctpid/www/tl/TL-pub-PPCC. html\#ab

16. Atkinson R, Flint J. Accessing hidden and hard-toreach populations: snowball research strategies. Guildord (UK): Social Research Update n 33; 2001.

17. Goffman E. Estigma: notas sobre a manipulação da identidade deteriorada. Rio de Janeiro: Zahar Editores; 1982.

18. Ferreira LC. Os fantasmas do vale: qualidade ambiental e cidadania. Campinas: Editora da Unicamp; 2003.

19. Paolielo MMB, Capitani EM, Cunha FG, Matsuo T, Carvalho MF, Sakuma A, Figueiredo BR. Exposure of children to lead and cadmium from a mining area of Brazil. Environmental Research 2002; 88(2):120-128.

20. Paoliello MMB, Capitani EM, Cunha FG, Carvalho MF, Matsuo T, Sakuma A, Figueiredo BR. Determinants of blood lead levels in an adult population from a mining area in Brazil. Journal de Physique IV 2003; 107(1):127-130.

21. Cunha FG, Figueiredo BR, Paoliello MMB, De Capitani EM, Sakuma AM. Human and environmental lead contamination in the Upper Ribeira Valley, southeastern Brazil. Terrae 2005; 2(1-2):28-36.
22. Lammoglia T, Figueiredo BR, Sakuma AM, Buzzo ML, Okada IA, Kira CS. Lead in food and soil from a mining area in Brazil and human exposure. In: Chinese Journal of Geochemistry 2006; Supplementary Issue dedicated to the 7th International Symposium on Environmental Geochemistry, Beijing:66.

23. Carvalho FM, Silvany Neto AM, Tavares TM, Costa ACA, Chaves CDR, Nascimento LD, Reis MA. Chumbo no sangue de crianças e passivo ambiental de uma fundição de chumbo no Brasil. Revista Panam Salud Publica 2003; 13(1):19-23.

24. Dos Anjos JASA. Avaliação da eficiência de uma zona alagadiça (wetland) no controle da poluição por metais pesados: o caso da Plumbum em Santo Amaro da Purificação/BA [tese]. São Paulo (SP): Escola Politécnica, USP; 2003.

25. Brasil. Ministério da Saúde (MS). Avaliação de risco à saúde humana por metais pesados - Santo Amaro da Purificação - Bahia. Brasília: Ministério da Saúde (MS); 2003. [Documento da Internet] [acessado 2008 jun 18]. Disponível em: http://portal.saude. gov.br/portal/arquivos/pdf/cap1_introducao.pdf

26. Pidgeon N, Kasperson RE, Slovic P, organizadores. The Social Amplification of Risk. Cambridge: Cambridge University Press; 2003.

27. Herber MW. Underlying concerns in land-use conflicts - the role of place-identity in risk percepetion. Environmental Science \& Policy 2004; 7(2):109116.

28. Rowe G, Frewer LJ. Evaluating Public Participation Exercises: A Research Agenda. Science, Technology \& Human Values 2004; 29(4):512-556.

Artigo apresentado em 23/05/2010

Aprovado em 13/08/2010

Versão final apresentada em 29/08/2010 